\title{
农田水利工程中防渗渠道施工工艺的应用
}

间世荣

昌吉市三屯河流域管理处

DOI:10.32629/hwr.v4i3.2850

[ 摘 要] 基于对农田水利工程中防渗渠道施工工艺应用的研究,首先, 阐述施工不当、地理环境、维护保养、土壤冻胀等是造成农田水利渠道 渗漏主要原因。然后, 分析农田水利工程防渗渠道施工工艺。最后, 为促使防渗渠道施工工艺能够在农田水利工程中将自身作用与价值发挥, 给 出加强地基处理工作、加强混凝土施工工作、加强施工准备工作等应用措施。

[关键词] 农田水利工程; 防渗渠道; 施工工艺

农业是我国发展过程中的重要组成部分, 农业的发展可以在很大程度 上促进我国社会的进步。在农业发展中农业灌溉是其中的重要工作, 在灌 溉过程中, 往往会通过农田水利渠道灌溉方式。这样不仅能够达到良好灌 溉效果, 同时提升水资源利用率。但是, 在农田水利工程中会出现渗漏问 题。渗漏问题的产生, 不仅影响灌溉工作的展开, 同时会造成水资源浪费。 为避免此类情况产生, 要加强对防渗渠道施工工艺的应用。所以, 本文将针 对农田水利工程中防渗渠道施工工艺的应用相应内容进行阐述。

\section{1 造成农田水利渠道渗漏原因}

造成农田水利渠道渗漏的原因有很多, 本文主要从以下几点进行分析 (如图一)：(1) 施工不当原因。从目前农田水利防渗渠道建设工作的开展 中不难看出, 许多施工人员并没有经过专业知识培训与技术培训。这一情 况的产生, 使得在不同的施工环节中会出现施工质量不过关的情况。施工 技术施工不规范, 此类问题的产生, 都会对后续水利工程质量产生影响, 从 而出现渠道渗漏问题。(2) 地理环境原因。在农田水利施工过程中, 相关工 作人员对于环境问题并没有进行详细分析与研究。因为在许多土地中, 会 存在一定的酸性物质与碱性物质, 此类物质在农田水利渠道的使用过程中 会产生腐蚀作用。腐蚀导致渠道中混凝土材料受到影响, 从而带来严重的 渗漏问题。(3) 维护保养原因。农田水利工程在建设后, 需要安排工作人员 定期做好工程的维护保养工作。但是, 相关部门并没有意识到维护保养工 作的重要作用。致使渠道中存在的问题没有被及时发现并解决, 原本的小 渗漏问题逐渐加重。(4) 土壤冻胀原因。通常情况下在农田水利建设工作 的开展中, 施工现场土壤中水分含量相对较高。在季节更替过程中, 土壤中 的水分会带来一定的冻胀问题。土壤冻胀会对混凝土质量造成影响, 渠道 渗漏问题也会随之产生。

\begin{tabular}{|c|c|}
\hline 原因 & 说明 \\
\hline 施工不当 & $\begin{array}{l}\text { 很多施工人员没有受过相关的技术培训, 缺乏专业技能, 施工操作不规范, 采用的施工技术较落后, } \\
\text { 造成住田水利渠道工程下降, 并使整个工程存在很多安全隐患。 }\end{array}$ \\
\hline 埋地环靚 & 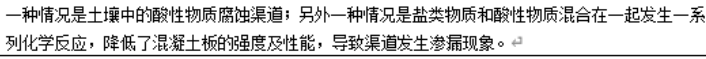 \\
\hline 维护不利 & 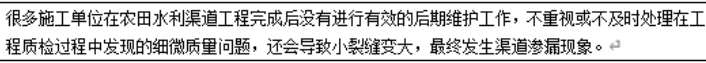 \\
\hline 冻胀因素 & 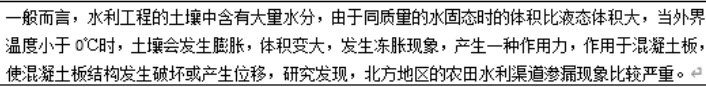 \\
\hline
\end{tabular}

\section{图一 农田水利渠道产生渗漏的原因}

\section{2 农田水利工程防渗渠道施工工艺分析}

在对农田水利工程防渗渠道施工工艺的分析过程中, 本文主要从以下 几点展开: (1) 在对渠道断面进行设计过程中, 要加强对公式的应用, 从而 对渠道水深、宽深等进行明确, 并掌握渠道的深宽比例。对于渠道深宽比 例要做好校核工作, 在最大程度上保证深宽比例的准确性与科学性。在此 基础上, 对渠道断面进行设计。(2) 在渠道放样工作的开展中, 需要展开挖
方与填方工作, 在这一过程中, 需要明确实际检测点与设计点之间的差异 情况。与此同时, 要在最大程度上保证土方的平整性, 使得放样规范得到保 障。除此之外, 在实际工作的开展中, 要按照防渗施工设计方案与图纸进行, 在最大程度上确保放样的合理性。(3) 加强夯实处理工作的展开, 夯实处理 步骤有三点, 分别是清渠、处理与夯实。要将渠床中存在的多余杂质、土 壤以及淤泥等及时清理干净。然后, 选择土壤进行填方工作, 土壤的选择要 确保其具备较强的防渗效果, 比如, 使用粘性土壤 ${ }^{[1]}$ 。最后的夯实处理, 要 加强对打夯机的应用。夯实处理工作对于保证防渗渠道施工工艺效果而言 具有重要作用, 因此, 在实际夯实处理中, 要结合渠道的不同, 对夯实程度 进行调整。(4) 填方施工对与防渗渠道施工工艺而言具有一定特殊性, 是工 艺中较为特殊的一个环节, 通常填方施工工作会将其应用在特殊渠床中。 比如, 渠床凹凸不平, 无法保证自身的平整性, 那么就要展开填方施工工 作。填方的位置主要是基底, 在完成基底填方后要及时对其进行夯实处理。 在夯实过程中, 要将夯实厚度控制在合理范围内, 一般保证在三十厘米左 右即可, 在完成夯实后, 要在最大程度上保证渠床平整性。(5) 加强混凝土 施工工作, 在进行混凝施工之前, 要严格按照施工实际情况与公式, 对混凝 土的配比进行计算, 确保其合理性。在施工过程中, 及时做好模板中的垃圾 清理与泥土清理工作。并对模板酒水, 保障模板湿润程度。在混凝土摚拌 期间, 要将摚拌时间控制在合理范围内, 搅拌时间过长或者过短都会对混 凝土质量产生影响, 具体混凝土的搅拌如图二。

\begin{tabular}{ccccc}
\hline \multirow{2}{*}{$\begin{array}{c}\text { 混凝土的 } \\
\text { 朋落度 } / \mathrm{cm}\end{array}$} & 摚拌机 & \multicolumn{3}{c}{ 搅拌机容量 $/ \mathrm{L}$} \\
\cline { 3 - 5 } & 类型 & $<250$ & $250 \sim 500$ & $>500$ \\
\hline \multirow{2}{*}{$\leqslant 3$} & 自落式 & 90 & 120 & 150 \\
& 强制式 & 60 & 90 & 120 \\
\hline \multirow{2}{*}{$>3$} & 自落式 & 90 & 90 & 120 \\
& 强制式 & 60 & 60 & 90 \\
\hline
\end{tabular}

图二: 混凝土搅拌

3 农田水利工程中防渗渠道施工工艺的应用措施

3. 1 加强地基处理工作

昌吉市三屯河流域管理想要在最大程度上促使防渗渠道施工工艺, 能 够在农田水利工程中发挥自身最大作用与及价值, 往往都会通过加强对地 基的处理。在农田水利渠道建设工作中, 最先考虑的问题就是地基处理问 题。保证地基处理质量, 才能避免渠道出现渗漏问题。地基质量对于保证 农田水利工程质量, 以及渠道质量而言具有重要作用。因此, 对于地基处理 工作要加强重视程度。在实际地基处理中, 可以从以下几点展开: (1) 在施 工之前要对施工现场的环境问题进行充分分析, 明确现场地质情况以及水 文情况等。因为, 不同地质条件情况会对地基施工工作产生不同影响 ${ }^{[2]}$ 。基 于此, 在施工之前要对土壤以及环境情况进行考虑与分析, 防止因为土壤 
等问题对施工质量产生影响。(2) 施工人员对于不同地基的处理方式都要 有明确把握, 这样才能更好应对地基问题。针对不同地基采取与之相适应 的处理方式, 从而在最大程度上保证地基施工质量, 为未来农田水利渠道 的使用打下良好基础。

3. 2 加强混凝土施工工作

通过混凝土施工工作的展开, 可以在很大程度上保证农田水利渠道质 量, 使得防渗渠道施工工艺能够将自身作用与价值充分发挥。在实际混凝 土施工工作的开展中, 可以从以下几点进行：(1) 做好模板施工工作。在混 凝土施工中模板施工是其中的重点工作内容, 因为, 在混凝土使用过程中, 需要构建模板。模板可以采取预制构件方式, 对于预制建筑要加强研究与 分析工作。在施工期间要确保材料质量, 材料质量会直接影响到建筑构件 质量。对于施工技术的使用, 要做好管理工作。通过监督管理工作的展开, 及时发现预支构件中存在的问题, 并给出相应调整措施, 确保预制构件质 量。(2) 混凝土材料配比会对农田水利渠道工程质量产生重要影响, 只有保 证配比的科学性与合理性, 才能确保渠道的能够达到良好的抗震效果与抗 渗能力。在这一过程中, 要注意以下几点问题: (1)确保水灰比设置的合理 性, 水泥、骨料是混凝土中的重要组成部分, 水泥以及骨料之间的配比, 会 影响混凝土强度大于性能。如果水灰比超过 0.6 , 那么会因为水分过多, 导 致出现蒸发问题出现从而产生洗孔。所以, 在水灰材料的配比中, 尽量要小 于 0.6 。(2)在因为水泥是混凝土施工中的重要组成部分, 因此, 水泥的购买 要从正规渠道, 并且确保水泥质量。一般情况下, 要选择低水热化水泥, 同 时能够实现对矿渣的有效处理。在骨料的选择中, 尽量选用颗粒物适中的 材料, 这样才能避免细孔情况的产生。(3) 做好拆模养护工作。在完成混凝 土浇筑工作后, 要及时对其进行固化。在实际固化过程中, 要避免受到其他 因素影响。除此之外, 要做好混凝土保护工作, 在实际保护中可以采取塑料 薄膜的方式, 使得混凝土构件质量得到保障。对于水量的使用, 要保证科学 性。避免水量过多或者过少, 会影响混凝土的正常使用, 并为后续农田水利 渠道的使用打下基础。

3. 3加强施工准备工作

防渗渠对于应力没有过多要求, 因此, 在对土壤固化过程中, 直接依靠 自然排水的方式即可, 这样就可以符合相应的工作需求。在该种要求体系 之下, 需要做好施工前准备工作。具体可以从以下几点展开:

(1) 加强施工设计准备工作。在施工工作开展之前, 相关施工人员能够 做好现场勘查工作, 对现场实际地质情况、灌溉设施情况以及总体布局情 况进行分析与明确, 从而制定相应施工计划, 确保施工计划的科学性与合
理性 ${ }^{[3]}$ 。在具体的施工计划中要保证全面性, 比如, 工程量、工程总量、工 程周期等。(2) 加强施工工程准备。施工工程准备工作主要是对土方展开 挖掘工作, 在对预建设位点土方进行提前开挖过程中, 要严格按照相应的 施工规划以及线路安排等内容展开。在完成开挖工作后, 要及时对其进行 晾晒, 在自然通风情况下, 保持晾晒三十天左右。晾晒完毕后通过强夯法的 方式, 对土壤进行集成加固, 做好浇筑外膜施工工作。在土方工程施工中, 要 保证直线规划、转角规划符合相应标准。(3) 加强施工材料准备工作。在施 工材料准备工作的开展中, 主要是加强施工材料准备与施工设备准备。施 工材料准备与设备设施准备, 要严格按照相关混凝土施工规范展开。对于 施工材料要及时做好监督管理工作, 确保材料使用合理性。在设备设施的 日常使用中, 需要做好维护与保养工作。在最大程度上保证设备设施的安 全稳定运行, 避免因为设备设施性能等原因, 影响防渗渠道质量。

3. 4 加强材料质量控制与质量检测工作

对于材料质量控制工作与质量检测工作, 需要相关工作人员能够给予 更多关注与重视。一般情况下, 材料质量控制包括对水泥质量的控制、骨 料资粮的控制等。比如, 在水泥材料质量控制工作的开展中, 要选择一个长 期合作的生产, 合作厂商为其提供水泥。厂商在每次水泥货物的提供过程 中, 都要提供相应的批次检测报告, 在最大程度上保证水泥原料质量。与厂 商之间形成良好合作关系, 能够为施工部门节省更多时间与精力。在质量 检测工作的开展中, 要严格按照相关规定进行, 及时发现在渠道施工中存 在的质量问题, 并给出相应解决措施, 确保渠道的安全稳定运行。

\section{4 结束语}

综上所述, 防渗渠道施工工艺对于农田水利工程施工而言具有重要作 用。因此, 相关工作人员对于防渗渠道施工工艺要有正确认识, 将其应用在 相应的施工环节中, 确保施工质量。

\section{[参考文献]}

[1]刘博成.浅埋深条件下渠道防渗施工排水技术分析[J].农业科技与 信息,2019,(19):109-110+112.

[2]谷健, 李锋, 魏加森.混凝土防渗渠道施工工艺在农田水利工程中的 应用[J].城市建筑,2019,16(09):149-150.

[3]晏得勋.农业工作中农田水利灌溉防渗渠道施工探讨 [J].中国建材 科技,2019,28(01):53-54.

\section{作者简介：}

间世荣(1978--), 男, 甘肃张掖人, 汉族, 大专, 中级工程师, 研究方 向: 农田水利工程; 从事工作: 水利工程管理。 